\title{
PC-Câmbio: Proposta de Atividade Lúdica e Desplugada Aplicando a Metodologia do Pensamento Computacional
}

\author{
Yuri da Silva Rosa \\ Placida G. S. Oliveira \\ \{ydsrosa,pgsdoliveira\}@inf.ufpel.edu.br \\ Curso de Graduação em Ciência da Computação \\ Centro de Desenvolvimento Tecnológico - UFPEL \\ Pelotas, Rio Grande do Sul, Brasil
}

\author{
Clause Fátima de Brum Piana \\ clausepiana@yahoo.com.br \\ Centro de Desenvolvimento Tecnológico - UFPEL \\ Pelotas, Rio Grande do Sul, Brasil
}

\section{RESUMO}

A importância do pensamento computacional (PC) no desenvolvimento de competências consolida-se como um método sistematizado e eficaz, promovendo o desenvolvimento do raciocínio lógico formal, multidisciplinar, incremental e aplicável via atividades lúdicas, pelo uso de fundamentos da computação. Este trabalho apresenta o relato de experiência da atividade denominada Aprendizagem de Trocas e Câmbios via Pensamento Computacional (PCCâmbio). A proposta PC-Câmbio está estruturada em três tarefas a serem desenvolvidas de forma lúdica e desplugada, visando promover aprendizagem na educação básica através da metodologia do PC. Em seu desenvolvimento, focou-se no uso de ações de câmbio para explorar habilidades do PC como abstração e decomposição, relacionadas principalmente a ambas as estratégias de lidar com operadores aritméticos e algébricos envolvendo números e expressões numéricas, sendo estas associadas a algoritmos de reconhecimento de padrões. Sua aplicação ocorreu em turma de 26 alunos do 4 o ano do ensino fundamental. E sua avaliação buscou quantificar ganhos/perdas, considerando duas abordagens: (i) avaliação baseada em testes aplicados após término de cada uma das três tarefas, incluindo as observações coletadas pelos agentes aplicadores; e (ii) a partir da discussão de resultados sobre pré e pós testes envolvendo conteúdos relevantes do currículo de escolas municipais do 40 ano do ensino fundamental. Neste contexto, a atividade PC-Câmbio contribui para qualificação da aprendizagem de alunos desde as séries iniciais frente às demandas de inovações tecnológicas, com suporte nos fundamentos da ciência da computação.

Fica permitido ao(s) autor(es) ou a terceiros a reprodução ou distribuição, em parte ou no todo, do material extraído dessa obra, de forma verbatim, adaptada ou remixada, bem como a criação ou produção a partir do conteúdo dessa obra, para fins não comerciais, desde que sejam atribuídos os devidos créditos à criação original, sob os termos da licença CC BY-NC 4.0.

EduComp'21, Abril 27-30, 2021, Jataí, Goiás, Brasil (On-line)

(c) 2021 Copyright mantido pelo(s) autor(es). Direitos de publicação licenciados à Sociedade Brasileira de Computação (SBC)

\author{
Renata H. S. Reiser \\ Simone A. C. Cavalheiro \\ Luciana Foss \\ Andre Rauber Du Bois \\ \{reiser, simone.costa,lfoss,dubois\}@inf.ufpel.edu.br \\ Programa de Pós-Graduação em Computação \\ Centro de Desenvolvimento Tecnológico - UFPEL \\ Pelotas, Rio Grande do Sul, Brasil
}

\author{
Ana Rita Mazzini \\ anarita.mazzini@gmail.com \\ Instituto de Física e Matemática - UFPEL \\ Pelotas, Rio Grande do Sul, Brasil
}

\section{PALAVRAS-CHAVE}

Pensamento Computacional, Computação Desplugada, Abstração e Representação de Dados, Reconhecimento de Padrões, Aprendizagem no Ensino Básico

\section{INTRODUÇÃO}

O pensamento computacional (PC) é uma metodologia para identificação de problemas e soluções baseada nos fundamentos da Ciência da Computação (CC). Segundo Wing [20], o PC envolve de sobremaneira a projeção de sistemas e compreensão do comportamento humano através da extração de conceitos fundamentais em CC. Tais conceitos fundamentam um conjunto de competências cognitivas aplicadas na resolução de problemas de forma interdisciplinar, potencializando a aprendizagem nas mais diversas áreas do conhecimento [21].

Segundo [21], os métodos baseados em PC envolvem a resolução de problemas, tanto computacionais quanto cotidianos, através dos conceitos fundamentais da ciência da computação. Consolidando-se assim como uma metodologia fundamental para aprendizagem, não só para cientistas da computação, pois envolve a reformulação de um problema difícil em um problema que saibamos resolver, mas sobretudo para alunos do Ensino Fundamental.

Em sua estruturação, os fundamentos do PC se apoiam em quatro importantes e interdependentes dimensões ou pilares [9] definidas como abstração, reconhecimento de padrões, decomposição e algoritmos, para suporte ao processo de formulação de soluções computacionalmente viáveis.

Reconhecendo a importância do PC no desenvolvimento de competências de forma multidisciplinar, este trabalho adota o PC como um método sistematizado e eficaz, visando não somente familiarizar, mas sobretudo preparar o aluno das séries iniciais frente às novas tecnologias, as quais já frequentemente estão presentes no seu dia a dia.

O estímulo ao desenvolvimento via aplicação de conceitos e habilidades do PC desde a infância busca contribuir em todo seu processo de desenvolvimento e formação, capacitando os alunos na resolução dos futuros problemas (profissionais, sociais e mesmo 
culturais). Consideram-se ainda, as experiências de organização lógica, interação social e o pensamento crítico construídas na sala de aula via metodologia baseada nos conceitos do PC.

Neste contexto, este trabalho introduz a descrição da atividade denominada Aprendizagem de Câmbios via Pensamento Computacional (PC-Câmbio) a qual está baseada em três tarefas desenvolvidas de forma lúdica e desplugada, visando promover aprendizagem de trocas/câmbios na educação básica, através da metodologia do PC.

Em seu desenvolvimento, esta etapa do trabalho focou no uso de ações de câmbio para explorar habilidades do PC como abstração e decomposição, relacionadas principalmente a ambas as estratégias de lidar com operadores aritméticos e algébricos envolvendo números e expressões numéricas, sendo estas associadas a algoritmos de reconhecimento de padrões.

Sua aplicação ocorreu em uma turma de 26 alunos do $4^{\mathrm{o}}$ ano do ensino fundamental de uma escola do município de Pelotas. Na sua avaliação buscou-se quantificar ganhos/perdas, aplicando procedimentos de avaliação, considerando ainda pré e pós testes sobre conteúdos relevantes do currículo do $4^{\mathrm{O}}$ ano do ensino fundamental. Neste cenário, a atividade PC-Câmbio visa promoção e qualificação da aprendizagem de alunos desde as séries iniciais, frente às demandas de inovações tecnológicas, com suporte nos fundamentos da Ciência da Computação.

\subsection{Principais Contribuições}

Este trabalho colabora com o relato de experiência da atividade PC-Câmbio, considerando etapas como a apresentação, o desenvolvimento e avaliação, visando qualificação das atividades discentes e colaboração para melhor preparação de alunos nas séries iniciais, frente às inovações tecnológicas, com suporte nos fundamentos da CC. As tarefas desta proposta se aliam à metodologia do PC, cujas habilidades:

(i) promovem do raciocínio lógico dedutível;

(ii) podem ser conquistados de forma incremental;

(iii) são passíveis de aplicação em grande maioria dos conteúdos de currículos das séries do ensino fundamental;

(iv) preparam para novas estratégias de aprendizagem integradas às novas tecnologias digitais;

(v) não apenas incrementando a aprendizagem discente, mas também inibindo sua retenção, ao longo do tempo.

Destacam-se as seguintes contribuições da proposta de atividades PC-Câmbio:

- Qualificação e orientação da aprendizagem discente via atividade supervisionada por profissionais como professores, educadores e alunos da graduação em cursos de computação, como Ciência da Computação e Engenharia da Computação.

- Identificação de principais dificuldades na aprendizagem de abstrações relacionadas às operações aritméticas/algébricas com números, sendo estas associadas a trocas/câmbios, passando pelo estudo de algoritmos de padrão e decomposição de dados.

- Promoção de metodologia do PC em atividades lúdicas e desplugadas ${ }^{1}$, promovida pela aplicação de ações de câmbio/troca em tarefas didaticamente organizadas.

\footnotetext{
${ }^{1}$ Técnica para desenvolver as habilidades do pensamento computacional, sem o uso de computadores [3]
}

- Na sequência, durante o desenvolvimento de novas atividades, apresentação a quantificação de ganhos/perdas, pela aplicação de procedimentos de avaliação das tarefas e uso de associações, a partir de conteúdos relevantes no Ensino Fundamental.

\subsection{Organização do Artigo}

Após esta introdução, tem-se primeiramente na Seção 2, a caracterização da proposta metodológica, incluindo os conceitos trabalhados abrangendo habilidades do PC e dados, contextualizando a escola e perfil da turma, reforçando ainda a atuação desplugada desta proposta.

Na Seção 3, são descritas as três tarefas desenvolvidas segundo a atividade PC-Câmbio: tabulando pontuações no joga pega-varetas; propondo estender e introduzir novas estratégias no joga trocavaretas e ainda, modelando o processo de desenvolvimento de animais domésticos.

A Seção 4 apresenta um sumário explicitando as relações entre as principais ações envolvidas nas tarefas com conceitos e habilidades do PC, as quais estão inseridas na Base Nacional Comum Curricular (BNCC).

Um relato da aplicação da atividade PC-Câmbio é reportado na Seção 5.

Na Seção 6, segue-se a apresentação e discussão dos resultados da aplicação da atividade PC-Câmbio.

$\mathrm{Na}$ Conclusão, seguem as considerações finais e a continuidade do trabalho.

\section{PC-CÂMBIO: CONCEPÇÃO DA ATIVIDADE}

$\mathrm{O}$ principal objetivo da atividade $\mathrm{PC}$-Câmbio é dar suporte à aprendizagem de quatro importantes conceitos do PC, sendo eles:

- Decomposição, promovendo a divisão do problema em partes menores para facilitar sua resolução;

- Abstração, objetivando reduzir a complexidade de um problema, desprezando o que não é importante e focando no que se mostra relevante;

- Algoritmos, formulando uma sequência de instruções objetivas para resolver problemas; e

- Reconhecimento de Padrões, identificando problemas semelhantes e selecionando padrões que facilitem a solução de problemas complexos com mais eficiência [5].

Apresentam-se na sequência, as etapas envolvendo a concepção, o desenvolvimento e o relato de aplicação da atividade proposta, trabalhando habilidades relacionadas a todos os quatro conceitos citados, e estimulando ainda o uso da relação de igualdade, relevante habilidade proposta na BNCC [13], compreendendo a ideia de igualdade na escrita de diferentes sentenças aritméticas, como adições e multiplicações.

Essa atividade também promove o desenvolvimento das habilidades sociais graças ao uso do trabalho em equipe, interação entre grupo e participação em sala de aula.

De forma similar a outros projetos $[4,10,11,16,19]$, no desenvolvimento da atividade PC-Câmbio, esforços também foram direcionados priorizando três contextos: 
- atuação desplugada, ampliando a oportunidade de ensino em ambientes carentes, sem laboratórios de computação e/ou restrito acesso à internet;

- criatividade e simplicidade, via uso de materiais simples, baratos e acessíveis, mas integrados ao currículo e à realidade das escolas públicas do Ensino Fundamental;

- promoção de atividades lúdicas e sem necessidade de conhecimentos prévios e/ou treinamentos em computação para participação discente no projeto.

Nas etapas iniciais da escolaridade, é importante que os estudantes compreendam os conceitos do PC através de experiências concretas [8,15], justificando-se então a opção de trabalhar a computação desplugada nos anos iniciais $\left(1^{\mathrm{o}}\right.$ ao $5^{\circ}$ ano). De acordo com [18], os alunos poderão desenvolver novos modelos mentais para as abstrações computacionais. E posteriormente, atividades aplicadas serão trabalhadas de forma mais sistemática, no ensino centrada nos anos finais $\left(6^{\circ}\right.$ ao $9^{\circ}$ ano) e através da programação $[2,6,12,14,17]$.

As atividades foram elaboradas junto ao projeto extensionista ExpPC $^{2}$ [7], tendo como principal objetivo disseminar o PC nas escolas de Ensino Fundamental e contando com a parceria de várias escolas no município de Pelotas. O relatório das atividades está disponível no site ${ }^{3}$ do Projeto ExpPC, para que possam ser reaplicadas por professores, em outras escolas de Ensino Fundamental.

\section{PC-CÂMBIO PROPOSTA DE TAREFAS}

A atividade PC-Câmbio propõe no seu desenvolvimento três tarefas estruturadas e distribuídas em 4 etapas, as quais foram aplicadas em encontros semanais, com duração média de uma hora-aula cada. As avaliações ocorrem ao final das tarefas, viabilizando observar quais conceitos foram mais bem compreendidos pelos alunos e permitindo uma análise estatística dos dados gerados nos experimentos desenvolvidos.

As tarefas que compõem a atividade PC-Câmbio estão descritas na sequência, de acordo com as etapas de seu desenvolvimento.

\subsection{Tabulando Pontuações no Jogo Pega-Varetas}

O jogo Pega-Varetas mostra a importância da representação de dados através das cores e valores das varetas, considerando uma sequência de instruções básicas desenvolvida em etapa única com duração de uma hora-aula.

- abstração $(\mathrm{AB})$ e uso de operações algébricas $(\mathrm{OP})$ e representação dos dados (RD), para correto preenchimento da tabela de pontuação, cálculos finais, implicando ainda na compreensão plena da associação de valores às cores;

- abordagem algorítmica (AL), na execução da sequência de regras para atingir objetivo do jogo;

- habilidades sociais (HS), adquiridas na interação com outro jogador, para definição de estratégias comuns para alcançar o objetivo, mas respeitando turnos e regras nas jogadas.

\footnotetext{
${ }^{2}$ Explorando o Pensamento Computacional para a Qualificação do Ensino Fundamenta ${ }^{3}$ https://wp.ufpel.edu.br/pensamentocomputacional
}

3.1.1 Metodologia. A primeira atividade desta tarefa consiste na estruturação da turma em grupos de 4 alunos, cada grupo responsável por um kit de jogo, que consiste em 2 conjuntos de pega-varetas (totalizando 41 varetas) e 4 folhas de pontuação, veja Figura 1.

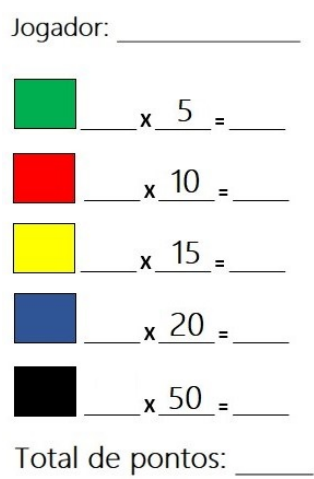

Figura 1: Pontuação das varetas por cor.

Na sequência, as regras do jogo de vareta são apresentadas:

(1) Jogo é realizado em turnos, onde os alunos precisam remover uma vareta de um monte sem movimentar as demais;

(2) Ao conseguir remover uma vareta, o aluno a guarda em seu montante e faz uma nova tentativa, caso falhe, perde a vez e passa para o próximo jogador;

(3) O jogador que retirar a vareta preta, respeitando as regras anteriores, poderá usá-la para auxiliar na retirada das outras varetas, nos próximos turnos do jogo;

(4) A pontuação dos alunos é obtida de acordo com os pesos (multiplicadores) apresentados na Figura 1.

No início do jogo, o primeiro jogador sorteado deve construir o monte da seguinte forma: segurar o feixe de todas as varetas perpendicular à mesa e, logo após soltar, para que as varetas caiam simultaneamente na mesa, veja Figura 2.

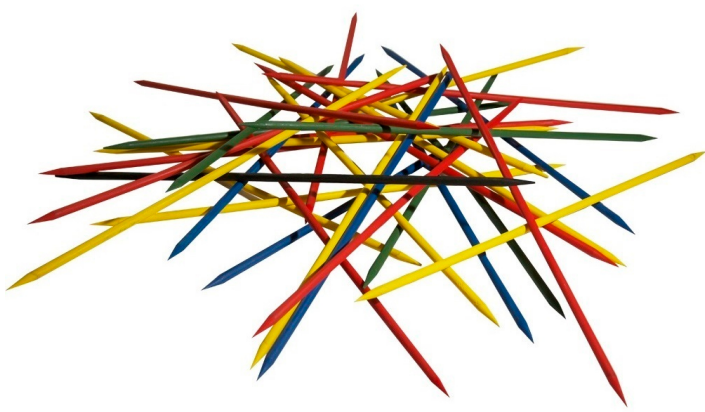

Figura 2: Iniciando jogada no Pega-varetas.

O jogo prossegue, alternando jogadores, até não haver mais varetas a serem pegas. Após o final do jogo, os jogadores preenchem a sua folha de pontuação com o número de varetas de seu montante, calculando a soma total de todas as multiplicações da quantidade de varetas obtidas pelo seu correspondente valor (Figura 1). O vencedor é o aluno que obtiver a maior pontuação. Na conclusão, foi aplicada 
a avaliação apresentada na Figura 3, para mensurar o aprendizado alcançado com a realização da tarefa.

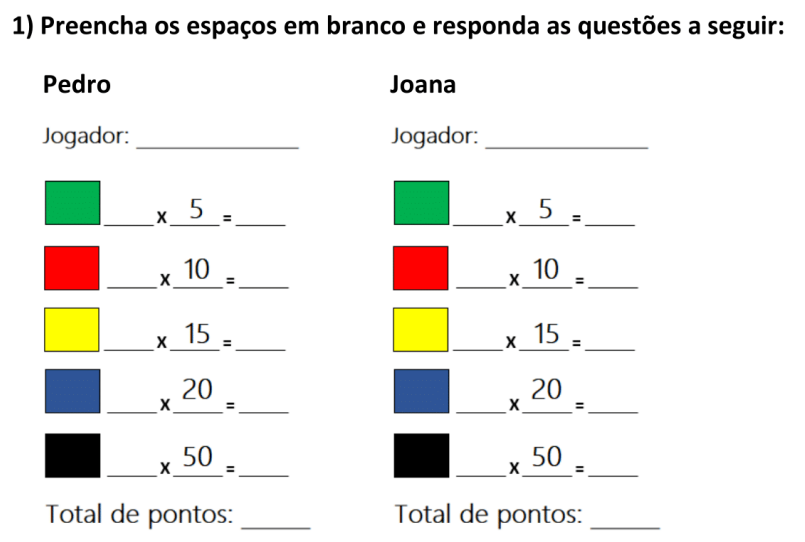

a) Quem venceu partida?

b) Quem pegou mais varetas?

Figura 3: Instrumento de avaliação da Tarefa 1.

\subsection{Propondo Estratégias no Jogo Troca-Varetas}

Como uma extensão das atividades da Tarefa 1, neste caso, busca-se consolidar os conceitos referentes às habilidades do PC. Em [1], o processo de abstração referente aos vários níveis do pensamento consiste na habilidade de maior relevância para desenvolvimento do PC. Assim, no contexto da atividade PC-Câmbio, tem-se:

- abstração na definição de padrões leva a definição de associações concretas entre elementos no jogo troca-varetas;

- decomposição do objetivo secreto em objetivos parciais que podem ser mais facilmente conquistados, até finalizar jogo;

- conceitos referentes às operações algébricas incluindo relações de igualdades e diferentes representações de dados (varetas), são construídos via manipulação das cores e valores dos dados.

Importante destacar a progressão de conceitos, onde aprender um novo conceito baseia-se na compreensão do conceito anterior e onde a progressão reflete a progressão do pensamento da criança à medida que ela pratica a atividade. Esta Tarefa 2 também foi desenvolvida em etapa única, com duração de uma hora-aula.

3.2.1 Metodologia. Nesta Tarefa 2 os alunos também são divididos em grupos de 4 membros, cada grupo recebendo um kit de varetas. A vareta de cor preta deve ser previamente removida do total de varetas (totalizando 40 varetas). Cada jogador recebe uma folha com propostas de troca como mostra a Figura 4.

E ainda, cada jogador terá um objetivo secreto, sorteado de um baralho, como mostra a Figura 5.

O jogo começa como na Tarefa 1, considerando quatro restrições:

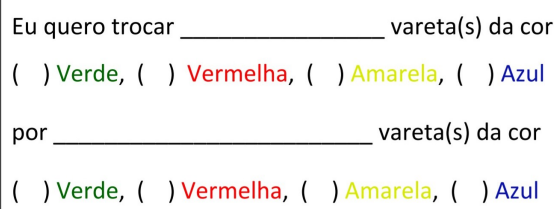

Figura 4: Proposta de troca.

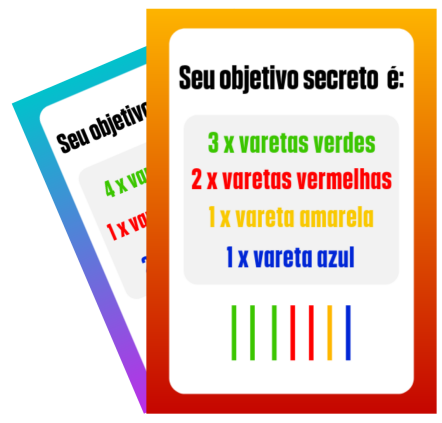

Figura 5: Objetivos secretos.

(i) A cada turno o jogador tem apenas uma tentativa de remover a vareta do montante;

(ii) Caso obtenha sucesso, coloca a vareta em seu montante e passa a vez;

(iii) Na falha da tentativa, o jogador também passará sua vez;

(iv) Quando finalizar a remoção das varetas, o jogo segue para a próxima etapa.

Na sequência, acontecem as trocas, forma pela qual os jogadores podem alcançar os objetivos secretos. A pontuação de cada cor de vareta segue a mesma da Tarefa 1, ilustrada na Figura 1. As trocas iniciam pelo jogador que obteve a menor pontuação na etapa anterior. E, se houver empate, a decisão é sorteada via o jogo par ou ímpar. Sendo as regras básicas descritas logo a seguir:

(1) Para uma troca é essencial que o jogador da vez preencha corretamente sua proposta de troca, baseando-se em seu objetivo;

(2) A troca deve sempre manter a equivalência em pontuação das partes.

(3) Cada jogador tem o direito de escolher um adversário para a troca;

(4) O adversário só poderá negar a proposta de troca, se a proposta estiver incorreta;

(5) A proposta é aprovada se a solicitação da troca das varetas for de uma única cor, e somente ocorre troca por varetas de uma outra cor.

Cada jogador da vez terá a chance de realizar uma troca, e na sequência, passará a vez para o jogador da esquerda. E assim, sucessivamente, até que o grupo consiga alcançar a maior quantidade de objetivos concluídos. A metodologia inclui a avaliação apresentada na Figura 6 ao final do encontro, mensurando o aprendizado discente. 


Valor das varetas:
Verde: 5 pontos
Vermelha: 10 pontos
Amarela: 15 pontos
Azul: 20 pontos

1 - Marque com um $X$ as trocas corretas:

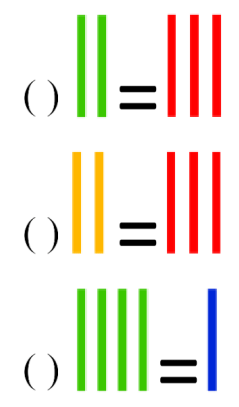

2 - Ligue os pontos da primeira coluna com os da segunda, de forma que as trocas sejam corretas:

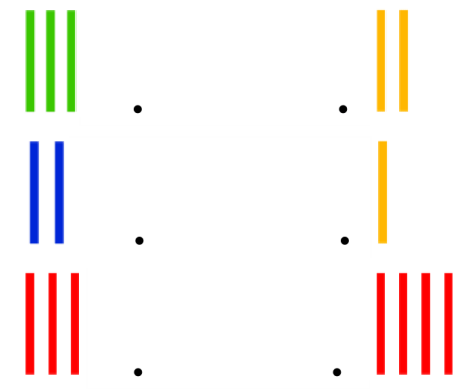

Figura 6: Instrumento de avaliação da Tarefa 2.

\subsection{Modelando o Processo de Desenvolvimento de Animais Domésticos}

Nesta terceira etapa da atividade PC-Câmbio são apresentadas as leis de mudança de representação de um determinado dado para outro, preservando classes, mas variando tipos, ao promover relações como quantidade/tamanho.

Esta mudança é construída através da análise de estágios modelando a dinâmica de desenvolvimento de animais domésticos. A Tarefa 3 foi desenvolvida em duas etapas, em dois encontros semanais e consecutivos de uma hora-aula cada, focando principalmente na relação de igualdade entre tipos/classes de dados, os quais são trabalhados na etapa 1, e, na etapa 2 , na avaliação das habilidades trabalhadas nas atividades aplicadas na primeira etapa.

3.3.1 Metodologia. A tarefa utiliza cartões de trocas, com um baralho de desafios compostos de imagens de animais em seus estágios de desenvolvimento. Cada desafio possui apenas uma espécie de animal em um de seus estágios de desenvolvimento. No caso de um animal jovem, ele se encontra em seu estágio 1, quando adulto no estágio 2 e idoso no estágio 3, conforme mostram as imagens na Figura 7, relacionados aos três estágios no desenvolvimento de animal da espécie canina (cão).

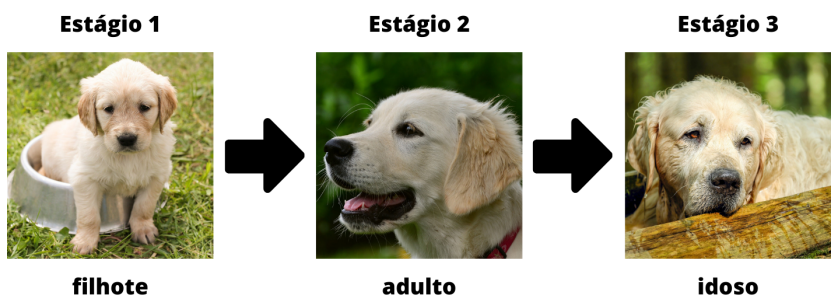

Figura 7: Estágios no desenvolvimento de um cão. Por Pixabay [Pixabay Lisence]. (https://bit.ly/31TbfkP, https://bit.ly/ 3kl2SWa, https://bit.ly/2TlObXe).

Pela Regra de Transformação (RT) é definida a associação entre uma quantidade de animais de mesmo estágio de determinada espécie, e os demais estágios no seu desenvolvimento.

Exemplificando na Figura 8, consideram-se animais da espécie felina (gatos). Nesta ilustração, observe que 1 gato de estágio 2 pode ser associado a 2 gatos jovens, ambos no estágio 1 , modelando a aplicação de uma RT.

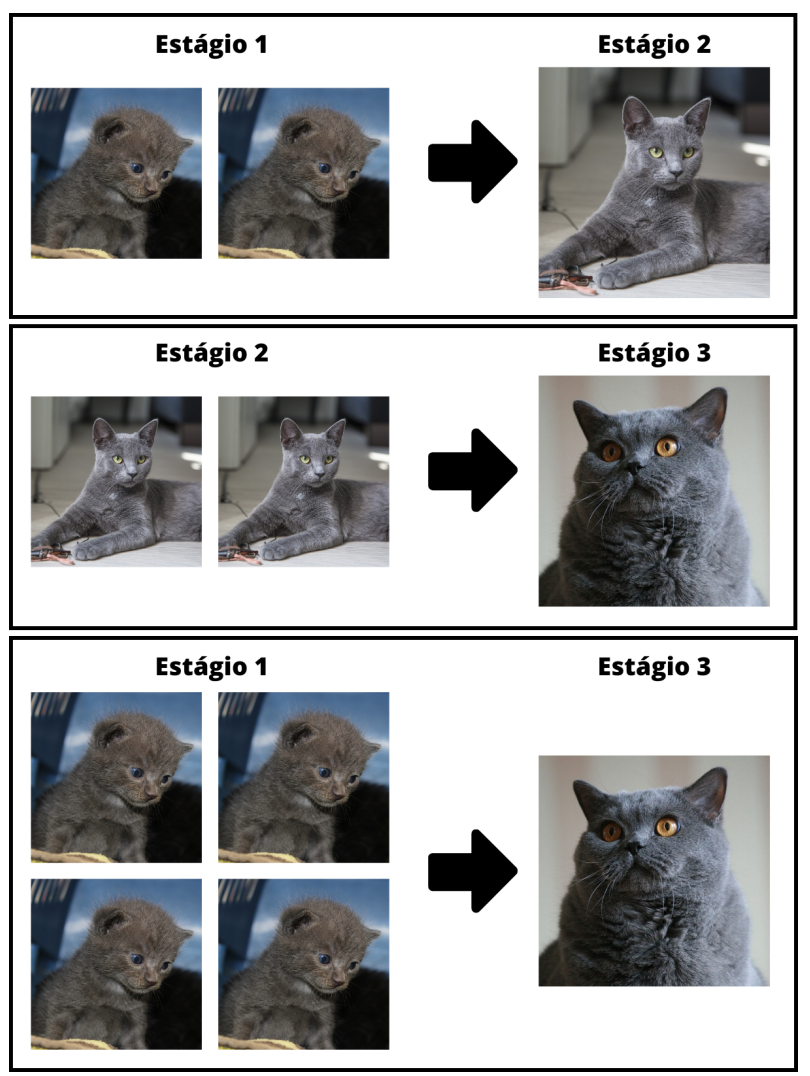

Figura 8: Regras de Transformação para gatos. Por Pixabay [Pixabay Lisence]. (https://bit.ly/31A7GQa, https://bit. ly/31AlzO6, https://bit.ly/31x2g8n). 
A variabilidade da quantidade de animais por estágios também foi trabalhada, mostrando que novas RTs podem ser construídas para diferentes espécies trabalhadas no jogo. Neste contexto, foram trabalhados habilidades e conceitos como reconhecimento de padrões, operações aritméticas, relações de igualdade e ainda habilidades sociais. Mais especificamente, foca-se especialmente em:

- ordenação, na identificação correta quanto aos estágios de desenvolvimento dos animais, desde o mais jovem até o mais velho e vice-versa;

- abstração, neste caso estendendo a associação ao considerar diferentes estágios de desenvolvimentos de animais na aplicação das RT;

- reconhecimento de padrões, pela análise de semelhanças identificando animais de mesma classe, e ainda capturando propriedades essenciais comuns a um conjunto de animais, como grupos de jovens e/ou adultos; e

- identificação de diferentes níveis de abstração, pelo reconhecimento de que um animal represente muitos outros animais mais jovens (no caso, indivíduo velho por grupos de jovens e/ou grupo de indivíduos maduros).

Veja a ilustração na Figura 9, onde tem-se que 9 animais jovens do tipo cão, no estágio 1, podem transformar-se em apenas 1 cão idoso, que já está no estágio 3 de seu desenvolvimento.

$\mathrm{O}$ agente/aplicador do jogo deve selecionar desafios para solucionar juntamente com a turma, certificando-se que cada RT esteja bem compreendida antes inicializar o jogo.

Nesta fase de apresentação do jogo, deve-se instigar a descoberta, através de perguntas, sobre questões de identificação correta quanto aos estágios de desenvolvimento dos animais. E assim, promover a aplicação corretamente das RTs para trocas de animais em estágio iniciais por animais em estágios mais avançados, e vice-versa.

Na mecânica do jogo, a turma é dividida em duas grandes equipes e o jogo acontece em turnos. Cada equipe escolhe um representante por rodada. Este representante seleciona aleatoriamente uma carta do baralho de desafios que será entregue ao aplicador da tarefa para ser mostrado a turma. Uma carta de desafio pode ser vista na Figura 10. O desafio proposto por esta carta é identificar quantos cães no estágio 1 ou 2 são necessários para se obter um cão no estágio 3.

$O$ representante e sua equipe devem selecionar a quantidade de cartas correspondente à solução correta, as quais estão distribuídas em montantes organizados por espécie de animal e seus respectivos estágios. Em seguida, a solução encontrada pela equipe deverá ser entregue ao aplicador para que possa conferir junto da turma se a resposta está certa. Quando correta, a equipe vence a rodada e ganha um ponto, caso contrário, a outra equipe terá a chance de responder ao desafio seguindo as mesmas regras. Caso ambas as equipes não solucionem o desafio, o aplicador deverá divulgar a solução. $\mathrm{O}$ jogo acaba quando uma das equipes alcança 5 pontos.

Na segunda etapa, tem-se a avaliação das atividades referentes a primeira etapa da Tarefa 3, que pode ser observada na Figura 11. Segue-se então, uma breve conversa de agradecimento a toda turma, nos momentos finais da aula, encerrando a aplicação da proposta PC-Câmbio.
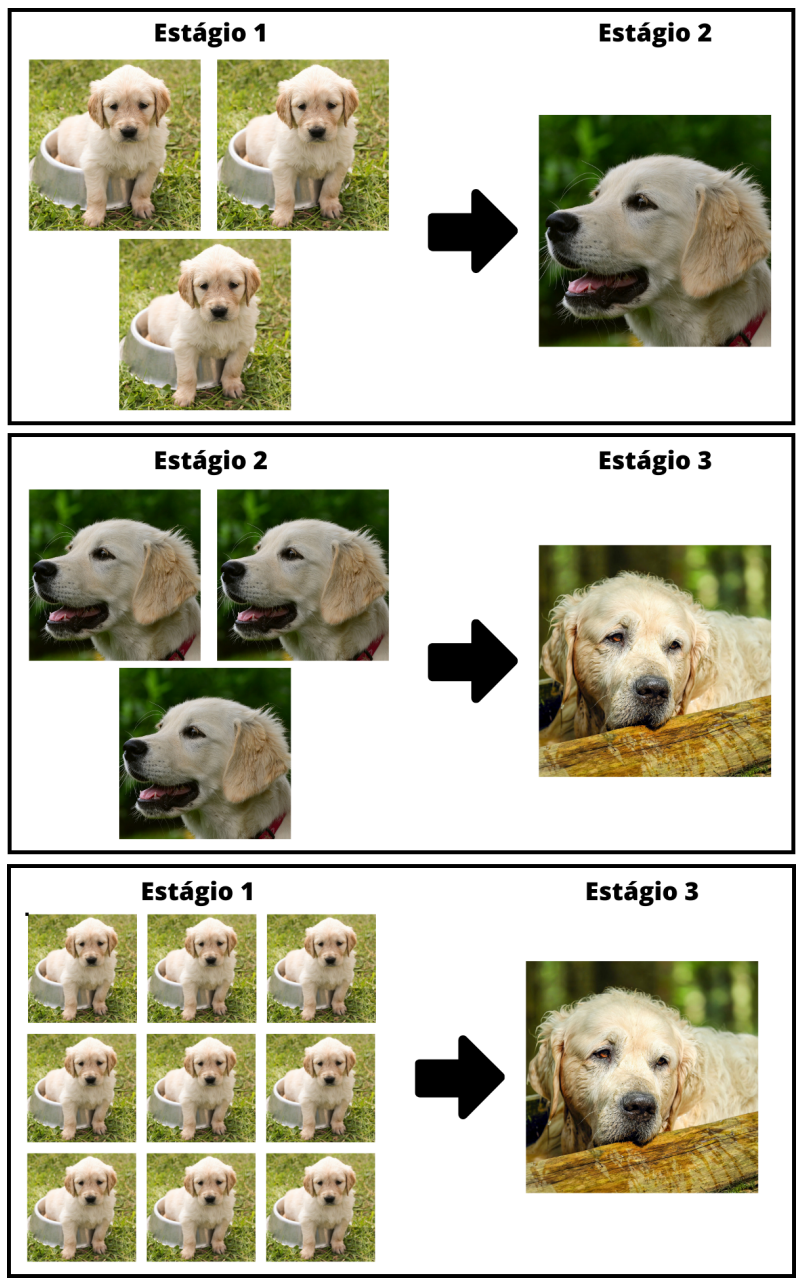

Figura 9: Regras de Transformação para cães. Por Pixabay [Pixabay Lisence]. (https://bit.ly/31TbfkP, https://bit.ly/ 3kl2SWa, https://bit.ly/2TlObXe).

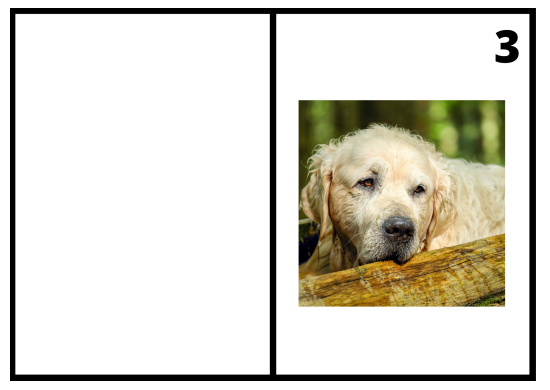

Figura 10: Exemplo de carta do baralho de desafios. Por Pixabay [Pixabay Lisence]. (https://bit.ly/2TlObXe). 


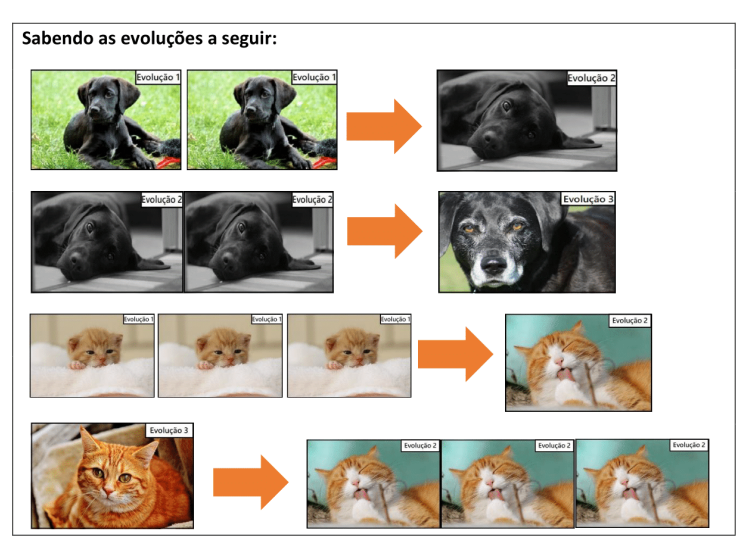

1 - Marque com um $X$ as trocas corretas:

( )
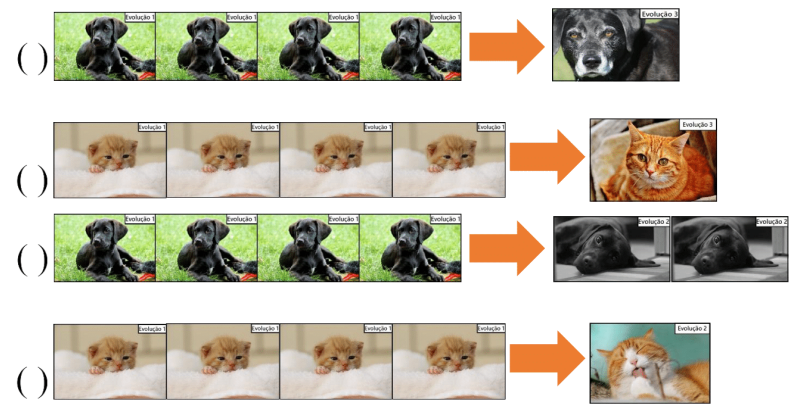

2 - Ligue os pontos da primeira coluna com os da segunda, de forma que as evoluções sejam corretas:
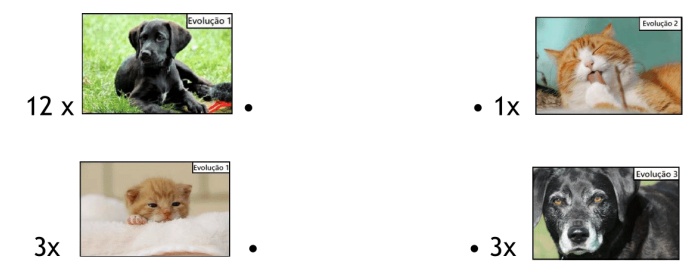

$6 x$
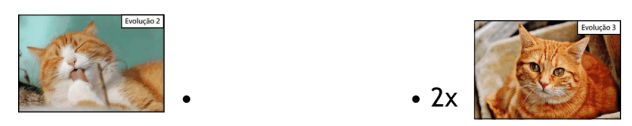

Figura 11: Instrumento de avaliação da Tarefa 3.

\section{PC-CÂMBIO: RELACIONANDO CONCEITOS DE PC E BNCC}

A Tabela 1 apresenta as relações entre as principais ações envolvidas nas tarefas com conceitos e habilidades do PC e da BNCC. Em cada tarefa foram identificadas as ações mais relevantes, descritas na primeira coluna da tabela. Cada ação é associada com os conceitos e habilidades trabalhados, dentre os seguintes: abstração (AB), decomposição (DE), algoritmos (AL), reconhecimento de padrões (RP), operações aritméticas (OA), relações de igualdade (RI) e habilidades sociais (HS).
Tabela 1: Relações Habilidades $\times$ Tarefas via PC e BNCC.

\begin{tabular}{lccccccc}
\hline Tarefas & AB & DE & AL & RP & OA & RI & HS \\
\hline Tarefa 1 & & & & & & & \\
Completar Tabela-Pontos & & X & X & & X & X & \\
Associar Valores-Cores & X & & & X & & & \\
Seguir Instruções-Jogo & & & X & & & & X \\
Tarefa 2 & & & & & & & \\
Interpretar Obj-Secreto & & X & & X & X & X & \\
Elaborar Prop-Troca & X & X & & X & X & X & \\
Identificar Prop-Correta & & & & & X & X & X \\
Detectar Obj-Atingido & X & & & & & & X \\
Seguir Instruções-Jogo & & & X & & & & X \\
Tarefa 3 & & & & & & & \\
Escolher Carta-Troca & X & X & & X & & X & \\
Interpretar RT & X & X & & X & & X & \\
Aplicar RT & & X & X & & X & X & \\
Seguir Instruções-Jogo & & & & X & & & X \\
\hline & & & & & & &
\end{tabular}

\section{PC-CÂMBIO: RELATO DA APLICAÇÃO}

As atividades lúdicas e desplugadas propostas foram aplicadas para uma turma de 26 alunos do $4^{\circ}$ ano do Ensino Fundamental, de uma escola pública da rede municipal de Pelotas ${ }^{4}$. As tarefas foram realizadas em encontros semanais de uma hora-aula de duração e envolveram todas as habilidades descritas na Seção 2.

Na primeira tarefa, o preenchimento da tabela de pontuação apresentada na Figura 1 implica na resolução cálculos que envolvem operações de multiplicação e soma.

Considerando o contexto da série onde a atividade foi aplicada, referente ao $4^{o}$ ano do Ensino Fundamental, esta tarefa contou com a ajuda dos agentes/aplicadores da atividade, além de revisões orais sobre as possíveis operações aritméticas envolvidas nas suas etapas. Assim, o jogo pode ser concretizado, e os alunos conseguiram realizar plenamente o instrumento de avaliação, com propostas de exercícios envolvendo as mesmas operações trabalhadas no desenvolvimento da tarefa.

O desenvolvimento da Tarefa 2 exigiu um nível alto de abstração dos alunos, desde a etapa de compreensão até aplicação das trocas, considerando ainda a interpretação do objetivo-secreto. Esta dificuldade gerou dispersão e desinteresse de alunos que não compreenderam o funcionamento pleno do jogo.

Como estratégia alternativa, reorganizamos a Tarefa 2 da proposta PC-Câmbio, contemplando outras atividades metodológicas, mas trabalhando as mesmas habilidades, porém com um nível de abstração mais adequado a turma de aplicação.

Optou-se pelo uso de animais domésticos tornando a atividade mais lúdica, gerando uma maior identificação e engajamento dos alunos, e ainda, a subdivisão em duas etapas, a primeira dedicada ao pleno desenvolvimento das habilidades, em diferentes níveis de abstração, e na segunda etapa, propondo o instrumento de avaliação organizado de forma objetiva, demandando menos tempo para responder as questões propostas, e, portanto mais rapidamente aplicado.

${ }^{4}$ Os responsáveis pelos alunos participantes assinaram o TCLE (Termo de Consentimento Livre e Esclarecido), CAAE: 73891417.0.0000.5317. 
Desta forma, percebeu-se uma melhor compreensão do jogo, ocasionando uma melhora na motivação da turma na realização das tarefas. Notou-se que as trocas e evoluções dos animais foram muito apreciadas pelos alunos e a disputa entre equipes em sala de aula tornou as tarefas bem mais interativas e divertidas, com participação de todos os alunos.

\section{PC-CÂMBIO: RESULTADOS E DISCUSSÃO}

Os resultados e discussões apresentados foram baseados em dois tipos de avaliações, descritas logo a seguir, em sequência.

\subsection{Avaliação Integrando Testes e Observações}

Esta primeira seção descreve a avaliação baseada em testes aplicados após términos de cada uma das três tarefas e das observações coletas pelos agentes aplicadores. Neste caso particular das observações, reportam-se os aspectos motivacionais, que poderiam incrementar o interesse dos alunos na continuidade, para a Tarefa 3 da atividade.

Esta análise da atividade compreendeu avaliação de três tarefas:

T1: Pega-Varetas, tabulando pontuações no jogo, com avaliação baseada em teste aplicado ao final do encontro;

T2: Pega-Varetas com trocas, propondo novas estratégias no jogo, com avaliação baseada em teste aplicado no final da aula, incluindo uma avaliação qualitativa mensurando a receptividade dos alunos relativa às duas primeiras tarefas.

T3: Trocas com evoluções, descrevendo o processo de desenvolvimento de animais domésticos, com avaliação baseada em aplicação de teste escrito, totalizando 10 pontos.

A avaliação baseada nas observações dos alunos também contribuiu para mudança do tema da Tarefa 3. Optou-se por uma tarefa mais lúdica, focando em animais domésticos, incrementando a participação da turma

A descrição da nota dos alunos nas avaliações das tarefas e da média geral dos alunos na atividade é apresentada na Tabela 2. O número de alunos variou entre as tarefas em razão de eventuais ausências nas aulas.

Tabela 2: Medidas descritivas de médias em Nota $\times$ Tarefa.

\begin{tabular}{c|cccc|ccccc}
\hline Tarefa & $\mathbf{n}$ & Média & DP & $\mathbf{C V}(\mathbf{\%})$ & Mínimo & $\mathbf{Q}_{\mathbf{1}}$ & $\mathbf{M d}$ & $\mathbf{Q}_{\mathbf{3}}$ & Máximo \\
\hline $\mathbf{1}$ & $\mathbf{2 4}$ & 6,9 & 2,6 & 38,1 & 0,0 & 5,7 & 7,0 & 9,5 & 10,0 \\
$\mathbf{2}$ & 25 & 7,6 & 2,8 & 36,2 & 0,0 & 6,5 & 8,3 & 10,0 & 10,0 \\
$\mathbf{3}$ & 23 & 8,2 & 2,2 & 27,0 & 2,0 & 7,0 & 9,0 & 10,0 & 10,0 \\
\hline Atividade & $\mathbf{2 6}$ & $\mathbf{7 , 5}$ & $\mathbf{2 , 1}$ & $\mathbf{2 8 , 0}$ & $\mathbf{2 , 0}$ & $\mathbf{6 , 0}$ & $\mathbf{7 , 9}$ & $\mathbf{9 , 2}$ & $\mathbf{1 0 , 0}$ \\
\hline
\end{tabular}

Nota: $\mathrm{n}=$ número de alunos; $\mathrm{DP}=$ desvio padrão; $\mathrm{CV}=$ Coeficiente de variação; $\mathrm{Q}_{1}=$ primeiro quartil; $M d=$ mediana; $Q_{3}=$ terceiro quartil.

A análise das notas por tarefa mostra que o desempenho dos alunos foi melhorando a cada tarefa. Na Tarefa 3 os alunos apresentaram as maiores notas (média $=8,2)$, com menor variação $(C V=27 \%)$.

A média geral da turma na atividade foi 7,5 , com valores variando de 2, 0 a 10, 0 pontos. Os quartis indicam que $50 \%$ dos alunos alcançaram média maior ou igual a 7,9 e $25 \%$, obtiveram média menor ou igual a 6,0 . Portanto, o desempenho geral da turma na atividade foi satisfatório.

\subsection{Avaliação via Pré e Pós Testes}

Outra avaliação foi desenvolvida com o propósito de avaliar qualitativamente o desempenho dos alunos que participaram da atividade PC-Câmbio.

Esta avaliação foi composta por dois testes, ambos com questões objetivas idênticas relacionadas às quatro principais habilidades do PC trabalhadas nesta atividade. Tais questões, bem como a organização destas, estão descritas na Figura 12.

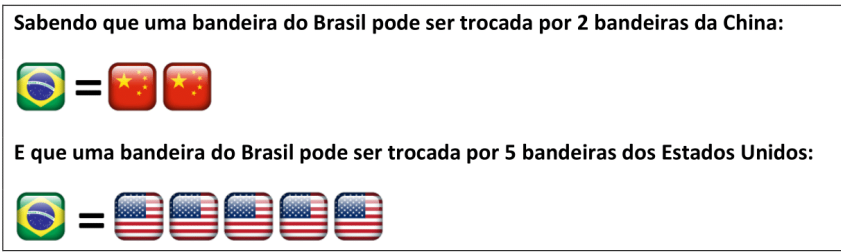

1 - Marque com um $X$ as trocas corretas:
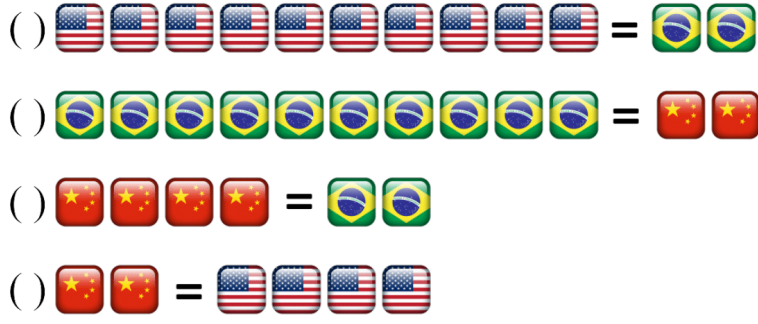

2 - Ligue os pontos da primeira coluna com os da segunda, de forma que as trocas sejam corretas:

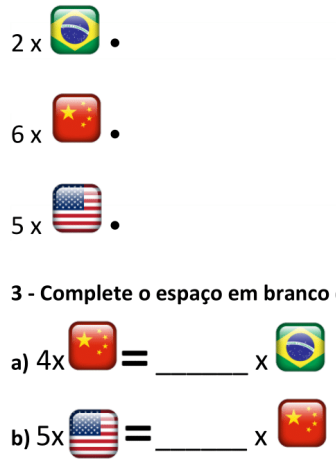

Figura 12: Pré e pós teste.

Os testes foram aplicados em dois momentos: na primeira aula, antes de iniciar a atividade (pré-teste), e na última aula, após a conclusão da atividade (pós-teste). A escala de pontuação do teste (de 0 a 10) e a diferença entre as notas alcançadas nos dois testes expressa o ganho (melhora) no desempenho do aluno.

A pontuação no pré-teste descreve a condição inicial dos alunos em relação às habilidades trabalhadas na atividade. Ambas medidas descritivas da nota, no pré e no pós-teste, e do ganho dos alunos, considerando a diferença entre as duas notas, estão apresentadas na Tabela 3. Nesta descrição foram considerados apenas os 22 alunos que realizaram os dois testes. 
Tabela 3: Medidas descritivas de médias nos pré- e pós-testes.

\begin{tabular}{c|cccc|ccc}
\hline Teste & $\mathbf{n}$ & Média & DP & CV (\%) & Mínimo & Mediana Máximo \\
& & & & & & & \\
\hline Pré & 22 & 7,9 & 2,38 & 30,33 & 2,3 & 9,0 & 10,0 \\
Pós & 22 & 8,2 & 2,33 & 28,48 & 2,3 & 8,9 & 10,0 \\
\hline Ganho & 22 & 0,32 & 5,12 & - & $-2,75$ & 0,0 & 7,75 \\
\hline
\end{tabular}

Nota: $\mathrm{n}=$ número de alunos; $\mathrm{DP}=$ desvio padrão; $\mathrm{CV}=$ Coeficiente de variação.

Analisando as notas dos alunos no pré-teste, observa-se que a turma alcançou média de 7, 9 pontos, com desvio padrão 2,38 pontos. No pós-teste a média aumentou para 8,2 pontos, mas o desvio padrão permaneceu praticamente o mesmo (2, 33 pontos). O ganho médio ( 0,32 pontos), indica que no pós-teste houve uma pequena melhora no desempenho geral da turma, mas o desvio padrão $(5,12$ pontos) revela que a variação do ganho dos alunos foi elevada.

Os gráficos de caixa apresentados na Figura 13 representam as distribuições dos dados das três variáveis, pré e pós-testes e incluindo variável ganho. Verifica-se que as notas dos testes apresentam assimetria negativa, significando que valores altos são mais homogêneos que valores baixos. Já a variável ganho possui distribuição aproximadamente simétrica, com presença de um valor atípico $(7,75)$. Esses gráficos também evidenciam que, em ambos os testes, pelo menos $50 \%$ da turma atingiram nota entre 9,0 e 10, 0 pontos.

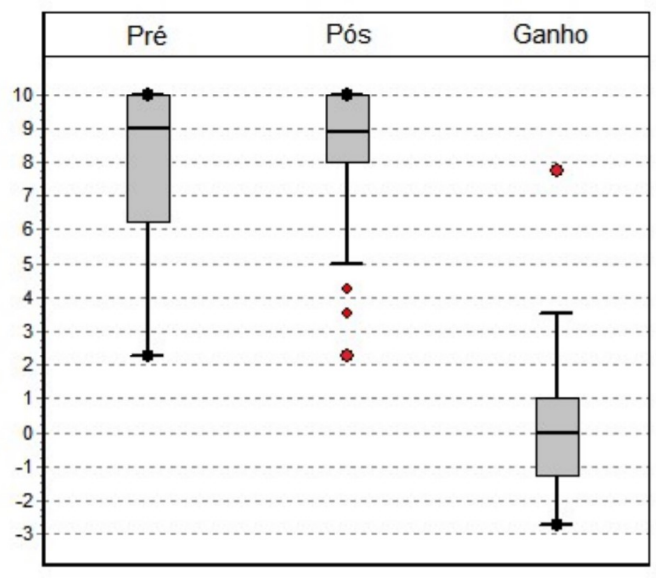

Figura 13: Distribuição das notas nos pré- e pós-testes. Obs: Ponto vermelho indica valor atípico na distribuição.

A significância do efeito da atividade sobre as habilidades específicas dos alunos pode ser verificada por meio de um teste de hipótese. Para tal, utilizou-se o teste T para amostras pareadas, com $\alpha=0,05$, cujos resultados estão resumidos na Tabela 4 .

A hipótese sob verificação no teste supõe que o ganho médio $(\mu)$ dos alunos não difere de zero, ou seja, $H_{0}: \mu=0$. Na prática essa hipótese significa que não houve incremento significativo no
Tabela 4: Teste-significância da variável ganho.

\begin{tabular}{cccccc}
\hline Ganho médio & Hipótese & Estatística T & Valor $\mathbf{p}$ & $\alpha$ & Decisão \\
\hline 0,32 & $\mu=0$ & 0,6596 & 0,5167 & 0,05 & Não Rejeita \\
\hline
\end{tabular}

desempenho dos alunos no pós-teste. O resultado do teste revela que a hipótese nula $\left(H_{0}\right)$ não foi rejeitada (valor $p>0,05$ ), significando que a atividade PC-Câmbio não promoveu melhora significativa nas habilidades específicas avaliadas.

É possível que esse resultado se deva à inadequação do teste aplicado para medir o incremento no desempenho do aluno. Essa hipótese se sustenta no fato de que $36 \%$ da turma alcançou nota máxima no pré-teste, o que inviabilizou, para esses alunos, a mensuração de ganho no pós-teste. Assim, para a aplicação desta atividade, sugere-se a elaboração de um novo teste contendo questões com maior sensibilidade para aferir o desempenho dos alunos.

\section{CONCLUSÃO}

A estratégia de desenvolver a atividade PC-Câmbio considerando as habilidades propostas via PC mostrou-se eficiente, promovendo novas soluções de problemas e focando no currículo do $4^{\circ}$ ano do Ensino Fundamental.

A experiência na concepção, desenvolvimento e aplicação bem como os resultados obtidos com a atividade PC-Câmbio fortalecem a proposta de integração do PC ao currículo brasileiro de educação. O relato das tarefas desenvolvidas segundo esta atividade, com poucos recursos e de maneira desplugada, mostra a capacidade de adaptação e inserção imediata dos fundamentos do PC para a promoção do ensino nas instituições educacionais.

Quanto a relevância qualitativa da proposta, obteve-se importantes conquistas:

(i) a integração entre os quatro pilares do PC, descritos aqui pelas habilidades de decomposição, abstração, algoritmos e reconhecimento de padrões;

(ii) o estímulo às habilidades de igualdade, aplicadas na comparação e associação de tipos/classes de dados; e ainda

(iii) o incentivo às habilidades sociais através da interação promovida pelas atividades realizadas em grupo.

Concluindo, na continuidade, três novas estratégias estão sendo avaliadas:

(1) melhorar as abordagens metodológicas para incremento da aprendizagem;

(2) trabalhar e nivelar o uso de abstrações nas tarefas de acordo com o ano escolar do público-alvo; e ainda

(3) estender a metodologia para outros anos abrangendo novos conteúdos do currículo do Ensino Fundamental.

\section{AGRADECIMENTOS}

O presente trabalho foi realizado com apoio da Coordenação de Aperfeiçoamento de Pessoal de Nível Superior - Brasil (CAPES) - Código de Financiamento 001, FAPERGS (PqG 02-2017), CNPq (PQ(309160 2019-7)), PREC e PRPPG / UFPel. Os autores agradecem também o apoio da Secretaria Municipal de Educação e Desporto de Pelotas. 


\section{REFERÊNCIAS}

[1] Alfred V. Aho and Jeffrey D. Ullman. 1992. Foundations of Computer Science, C Edition. Computer Science Press / W. H. Freeman. http://i.stanford.edu/ $\% 7$ Eullman/focs.html

[2] Thais Almeida, José Netto, Romero Silva, and Tiago Custódio. 2017. Laboratório Remoto de Robótica como Elemento Motivador para a Aprendizagem de Programação. Brazilian Symposium on Computers in Education (Simpósio Brasileiro de Informática na Educação - SBIE) 28 (2017), 665-674. https://brie.org/pub/index.php/sbie/article/view/7595

[3] Tim Bell, Ian H. Witten, and Mike Fellows. 2011. Computer Science Unplugged. Creative Commons Attribution-NonCommercial-NoDerivs. https://classic. csunplugged.org/books/

[4] Christian Puhlmann Brackmann. 2017. Desenvolvimento do pensamento computacional através de atividades desplugadas na educação básica. Ph.D. Dissertation. Programa Pós-Graduação em Informática na Educação. Universidade Federal Do Rio Grande Do Sul.

[5] British Broadcasting Corporation. 2020. Introduction to computational thin king. Disponível em: https://www.bbc.co.uk/bitesize/guides/zp92mp3/revision/1. Acesso em: 05-06-2020.

[6] Thaise Costa, Fábio Cristiano, Patrícia Rocha, and Danielle Danielle. 2017. O Ensino de Linguagem de Programação na Educação Básica Através da Robótica Educacional: Práticas e a Interdisciplinaridade. Anais do Workshop de Informática na Escola 23 (2017), 687-694. https://www.br-ie.org/pub/index.php/wie/article/ view/7287

[7] ExpPC. 2020. Explorando o Pensamento Computacional para a Qualificação do Ensino Fundamental. Disponível em: https://wp.ufpel.edu.br/ pensamentocomputacional/pt. Acesso em: 15-06-2020.

[8] Ana Ferreira, André Melhor, Jandiaci Barreto, Luiz Paiva, and Ecivaldo Matos. 2015. Experiência Prática Interdisciplinar do Raciocínio Computacional em Atividades de Computação Desplugada na Educação Básica. Anais do Workshop de Informática na Escola 21 (2015), 256-265. https://br-ie.org/pub/index.php/ wie/article/view/5032

[9] Shuchi Grover, Stephen Cooper, and Roy Pea. 2014. Assessing computational learning in K-12. In Innovation and Technology in Computer Science Education Conference 2014, ITiCSE '14, Uppsala, Sweden, June 23-25, 2014, Åsa Cajander Mats Daniels, Tony Clear, and Arnold Pears (Eds.). ACM, 57-62. https://doi.org/ $10.1145 / 2591708.2591713$

[10] Graziela Guarda and Ione Goulart. 2018. Jogos Lúdicos sob a ótica do Pensamento Computacional: Experiências do Projeto Logicamente. In Simpósio Brasileiro de Informática na Educação. 486-495.

[11] Mychelline Souto Henrique, Felipe Oliveira Miranda Cunha, Adelito Borba Farias, and Pasqueline Dantas Scaico. 2013. Proposta para Construção de Sequências Didáticas para aulas de Matemática com uma Atividade de Computação Desplugada. In Memorias XVIII Congreso Internacional de Informática Educativa. 369-374.

[12] Ricartty Martins, Ronaldo Reis, and Anna Marques. 2016. Inserção da programação no ensino fundamental Uma análise do jogo Labirinto Clássico da Code.org através de um modelo de avaliação de jogos educacionais. Anais do Workshop de Informática na Escola 22 (2016), 121-130. https://www.brie.org/pub/index.php/wie/article/view/6609

[13] MEC. 2018. Base Nacional Comum Curricular. Disponível em: http:// basenacionalcomum.mec.gov.br/abase. Acesso em: 15-06-2020.

[14] Manasses Neto, Camila Santos, Edmar Souza, and Marcos Fonseca. 2018. Robótica educacional uma ferramenta para ensino de lógica de programação no ensino fundamental. Anais do Workshop de Informática na Escola 24 (2018), 315-322. https://www.br-ie.org/pub/index.php/wie/article/view/7900

[15] Placida Oliveira, Gean Brandão, Luciana Foss, Andre Bois, Marilton Aguiar, Renata Reiser, Clause Piana, and Ana Mazzini. 2019. Proposta e Aplicação de Atividades para o Desenvolvimento das Habilidades de Organização de Informação e Pensamento Algorítmico. Anais do Workshop de Informática na Escola 25 (2019), 618-627. https://www.br-ie.org/pub/index.php/wie/article/view/8557

[16] Gustavo Santos, Wine Silva, Simone Cavalheiro, Luciana Foss, Marilton Aguiar Ana Pernas, Andre Bois, and Renata Reiser. 2015. Proposta de atividade para o quinto ano do ensino fundamental: Algoritmos Desplugados. In Workshop de Informática na Escola. 246-255.

[17] Josiane Soares, Rafael Cerci, and Helio Monte-Alto. 2016. Clube de programação e oficinas com o Scratch: um relato de experiência. Anais do Workshop de Informática na Escola 22 (2016), 958-962. https://www.br-ie.org/pub/index.php/wie/ article/view/6618

[18] Sociedade Brasileira de Computação. [n.d.]. Diretrizes para Ensino de Com putação na Educação Básica. Disponível em: http://sbc.org.br/documentosda-sbc/summary/203-educacao-basica/1220-bncc-em-itinerario-informativocomputacao-2. Acesso em: 11-06-2020.

[19] Jéssica Souza and Alba Lopes. 2018. Estimulando o pensamento computacional e o raciocínio lógico no ensino fundamental por meio da OBI e computação desplugada. In Simpósio Brasileiro de Informática na Educação. 1893-1897.

[20] Jeannette Wing. 2006. Computational Thinking. Commun. ACM 49 (2006), 33-35.
[21] Jeannette M. Wing and Dan Stanzione. 2016. Progress in computational thinking, and expanding the HPC community. Commun. ACM 59, 7 (2016), 10-11. https: //doi.org/10.1145/2933410 